\title{
Intraspecific variation in the cochleae of harbour porpoises (Phocoena phocoena) and its implications for comparative studies across odontocetes
}

\author{
Maria Clara Iruzun Martins ${ }^{\text {Corresp., 1,2 }}$, Travis Park ${ }^{2,3}$, Rachel Racicot ${ }^{4,5,6,7}$, Natalie Cooper ${ }^{2}$ \\ 1 Division of Biosciences, University College London, University of London, London, United Kingdom \\ 2 Department of Life Sciences, Natural History Museum, London, United Kingdom \\ 3 Department of Earth Sciences, University of Oxford, Oxford, United Kingdom \\ 4 Forschungsinstitut und Naturkundemuseum, Senckenberg der SNG, Frankfurt am Main, Germany \\ 5 The Dinosaur Institute, Natural History Museum of Los Angeles County, Los Angeles, California, United States of America \\ 6 Department of Earth and Environmental Sciences, Vanderbilt University, Nashville, Tennessee, United States of America \\ 7 Department of Zoology, Smithsonian Museum of Natural History, Washington, District of Columbia, United States of America \\ Corresponding Author: Maria Clara Iruzun Martins \\ Email address: maria.martins.15@ucl.ac.uk
}

In morphological traits, variation within species is generally considered to be lower than variation among species, although this assumption is rarely tested. This is particularly important in fields like palaeontology, where it is common to use a single individual as representative of a species due to the rarity of fossils. Here, we investigated intraspecific variation in the cochleae of harbour porpoises (Phocoena phocoena). Intraspecific variation of cochlear morphology is well characterised among odontocetes (toothed whales) because of the importance of the structure in echolocation, but generally these studies use only a single cochlea to represent each species. In this study we compare variation within the cochleae of 18 specimens of $P$. phocoena with variations in cochlear morphology across 51 other odontocete species. Using both 3D landmark and linear measurement data, we performed Generalised Procrustes and principal component analyses to quantify shape variation. We then quantified intraspecific variation in our sample of $P$. phocoena by estimating disparity and the coefficient of variation for our 3D and linear data respectively. Finally, to determine whether intraspecific variation may confound the results of studies of interspecific variation, we used multivariate and univariate analyses of variance to test whether variation within the specimens of $P$. phocoena was significantly lower than that across odontocetes. We found low levels of intraspecific variation in the cochleae of $P$. phocoena, and that cochlear shape within $P$. phocoena was significantly less variable than across odontocetes. Although future studies should attempt to use multiple cochleae for every species, our results suggest that using just one cochlea for each species should not strongly influence the conclusions of comparative studies if our results are consistent Peer] reviewing PDF | (2019:08:40803:2:0:CHECK 5 Mar 2020) 
across Cetacea. 
1

2

3

4 5

$6{ }^{1}$ Division of Biosciences, University College London, University of London, Gower Street,

7 Bloomsbury, London, WC1E 6BT, UK.

82 Department of Life Sciences, Natural History Museum London, Cromwell Road, London, SW7

9 5BD, UK.

$10{ }^{3}$ Department of Earth Sciences, University of Oxford, 3 South Parks Road, Oxford, OX1 3AN,

11 UK.

124 Forschungsinstitut und Naturkundemuseum, Senckenberg der SNG, Senckenberganlage 25,

1360325 Frankfurt am Main, Germany

145 The Dinosaur Institute, Natural History Museum of Los Angeles County, Los Angeles, CA

15 90007, USA.

16 17 USA.

18

20

21

22

23

24
7 Department of Zoology, Smithsonian Museum of Natural History, Washington, DC 20560, USA.

${ }^{6}$ Department of Earth and Environmental Sciences, Vanderbilt University, Nashville, TN 37240,

*Corresponding author: maria.martins.15@ucl.ac.uk implications for comparative studies across odontocetes. 
25 In morphological traits, variation within species is generally considered to be lower than

26 variation among species, although this assumption is rarely tested. This is particularly important

27 in fields like palaeontology, where it is common to use a single individual as representative of a

28 species due to the rarity of fossils. Here, we investigated intraspecific variation in the cochleae

29 of harbour porpoises (Phocoena phocoena). Interspecific variation of cochlear morphology is

30 well characterised among odontocetes (toothed whales) because of the importance of the

31 structure in echolocation, but generally these studies use only a single cochlea to represent

32 each species. In this study we compare variation within the cochleae of 18 specimens of $P$.

33 phocoena with variations in cochlear morphology across 51 other odontocete species. Using

34 both 3D landmark and linear measurement data, we performed Generalised Procrustes and

35 principal component analyses to quantify shape variation. We then quantified intraspecific

36 variation in our sample of $P$. phocoena by estimating disparity and the coefficient of variation for

37 our 3D and linear data respectively. Finally, to determine whether intraspecific variation may

38 confound the results of studies of interspecific variation, we used multivariate and univariate

39 analyses of variance to test whether variation within the specimens of $P$. phocoena was

40 significantly lower than that across odontocetes. We found low levels of intraspecific variation in

41 the cochleae of $P$. phocoena, and that cochlear shape within $P$. phocoena was significantly less

42 variable than across odontocetes. Although future studies should attempt to use multiple

43 cochleae for every species, our results suggest that using just one cochlea for each species

44 should not strongly influence the conclusions of comparative studies if our results are consistent

45 across Cetacea.

46

\section{Introduction}

48

49 Intraspecific variation, the diversity of genotypes and phenotypes within a single species, is a

50 key component of adaptation and evolution by natural selection (O'Dell \& Rajakaruna, 2011; 
51 Des Roches et al., 2018). Intraspecific variation includes variation related to size, allometry, sex,

52 and differences related to environment or genetics. It can influence community structure and

53 ecosystem function as much as interspecific variation (Des Roches et al., 2018). Within species,

54 there can be variation in predator defences, parasite resistance, resource manipulation and

55 many more, all of which can alter the number and strength of interactions, shifting the dynamics

56 of an ecosystem (Bolnick et al., 2011). Intraspecific variation also allows local adaptation and

57 the formation of ecotypes leading to phenotypic or genotypic divergence (Ishikawa, Onoda \&

58 Hikosaka, 2007; O’Dell \& Rajakaruna, 2011).

59

60 For most morphological traits, it is assumed that degrees of intraspecific variation are generally

61 smaller than those of interspecific variation. Nevertheless, in many studies this assumption is

62 not (or cannot be) tested because of logistical constraints, for example, where using multiple

63 specimens for each species is not feasible due to time or cost restrictions, or because samples

64 are limited. Palaeontological studies, for example, commonly use a single individual as

65 representative of a whole population or species because of the rarity of fossils (Ekdale \&

66 Racicot, 2015; Ekdale, 2016; Park et al., 2017a; Gonzales, Malinzak \& Kay 2018; Marx et al.,

67 2018; Racicot et al., 2019).

68

69 One field where this assumption has been made is the study of cetacean cochleae. The

70 cochlea, the organ of hearing, is a complex structure with a vital role in species survival (Cantos

71 et al., 2000). Odontocetes (toothed cetaceans) are reliant on their hearing abilities using

72 echolocation for feeding, communicating and navigating their habitat, among other functions

73 (Ketten, 1992a; Ketten, 1992b). Most cross-species studies of cetacean cochlear morphology

74 use only one cochlea for each species (e.g. Luo \& Marsh, 1996; Ekdale \& Racicot, 2015; Park,

75 Fitzgerald \& Evans, 2016; Churchill et al., 2016) due to the rarity of specimens in natural history

76 collections and because $\mu \mathrm{CT}$ scanning them takes time and money. Many studies also focus on

Peer) reviewing PDF | (2019:08:40803:2:0:CHECK 5 Mar 2020) 
77 using the cochlea to study interspecific variation among mammal groups (Ekdale \& Rowe, 2011;

78 Ekdale 2013, Benoit et al., 2015; Billet, Hautier \& Lebrun, 2015; Ekdale, 2016; Costeur, et al., 79 2018; Racicot, et al. 2016; Racicot, Darroch \& Kohno, 2018) rather than just within cetaceans.

80 However, increasing numbers of studies are using cochlear morphology (e.g. number of turns, 81 shape of endolymphatic sac) for phylogenetic purposes using geometric morphometrics (e.g.

82 Spoor et al., 2007; Billet, Hautier \& Lebrun, 2015; Mennecart \& Costeur, 2016; Costeur et al., 83 2018), which could have implications in comparative studies (Ekdale, 2010; Ekdale, 2015;

84 Thean, Kardjilov \& Asher, 2017).

85

86 Here, we tested whether intraspecific variation is a major confounding factor in cross-species 87 analyses by comparing morphological variation among the cochleae of 18 specimens of harbour porpoise (Phocoena phocoena) with those across 51 other species of odontocete. Specifically we investigate whether variation within $P$. phocoena cochleae is significantly lower than variation across all odontocete cochleae. Intraspecific variation has not been quantified relative to interspecific variation in odontocete cochleae. Previous studies have either briefly noted clustering of taxa in morphospace, differences between left and right ears (Racicot, Darroch \& Kohno, 2018), or only focused on population-level differences within a single species (Schnitzler et al., 2017). Our 18 conspecific specimens represent a large advance in our ability to quantify intraspecific variation in this feature.

\section{Material and Methods}

DATA COLLECTION

100 We chose the harbour porpoise (Phocoena phocoena) for this study because of the large

101 number of specimens in natural history collections making it possible to obtain a large sample

102 size for the species, something that is not available for most odontocetes. We assumed that 
103 results from $P$. phocoena can be generalised across odontocetes, but were unable to test this

104 assumption with the available data.

105

$1063 D$ shape data

107 TP collected the majority of the 3D shape data for an earlier paper (Park et al., 2019). 18

108 cochleae of $P$. phocoena were added to this study by MCIM (Table S1). For all cochleae we

109 obtained $\mu$ CT scans of the periotics - the bone containing the inner ear - of 52 species

110 (comprising $94 \%$ of extant genera) of odontocetes by imaging osteological specimens from

111 museum collections. Scan parameters for cochleae of $P$. phocoena are available in Table S2

112 and scan parameters for previously collected data on the other species are available from Park

113 et al. (2019). For this study we obtained periotics from 18 specimens of $P$. phocoena. Of these

11415 are from the left-hand side of the skull, and three from the right-hand side; 17 are from the

115 UK coast, and one is from the USA coast; four are female, five are male, and nine are unsexed 116 (see Table S3). All specimens are adult animals.

118 Using these data, we reconstructed 3D models of the inner ears using the segmentation and 119 thresholding editors in Avizo 9.0 (Visualization Sciences Group-a FEl Company, 2016), and 120 then cleaned the resulting 3D models using Geomagic Wrap ${ }^{\circledR}$ (3D Systems, 2017). Next we 121 landmarked the digital models with 40 sliding semilandmark curves comprising a total of 361 122 landmarks (Figure 1), using IDAV Landmark (Wiley, 2005). The position of these curves 123 followed the protocols of Costeur et al. (2018), using only the curves from the cochlea because 124 the semi-circular canals are not phylogenetically or ecologically informative in odontocetes 125 (Costeur et al., 2018). Landmarks were placed by a single investigator (TP) to avoid multi-user 126 bias in placement. Finally we exported coordinates from the landmarked models as .pts files 127 from IDAV Landmark (Wiley, 2005). 


\section{Geometric morphometrics}

130 We performed all geometric morphometric analyses in $\mathrm{R}$ version 3.4.3 ( $\mathrm{R}$ Core Team, 2019), 131 using the R package GEOMORPH (Adams, Collyer \& Kaliontzopoulou, 2018). First, we used 132 Generalised Procrustes Analysis (GPA) to remove the effects of position, scale and orientation. 133 The semilandmarks were 'slid' along their tangent vectors between adjacent semilandmarks 134 until their positions minimised the shape difference between specimens (using the Procrustes 135 distance criterion), to reduce the effect of their initially arbitrary placement (Bookstein et al., 136 1999; Gunz, Mitteroecker \& Bookstein 2005; Adams, Rohlf \& Slice, 2013). We then performed a 137 principal component analysis (PCA) on the resulting Procrustes coordinates using the 138 'plotTangentSpace' function; and used these principal components (PCs) in further analyses. 139

\section{Linear measurements}

141 One of us (MCIM) took the following measurements of the cochlea (Figure 2) in Avizo 9.2.0 142 using the Measure and Spline Probe tools and following protocols from Park, Fitzgerald \& 143 Evans (2016): (1) cochlear height; (2) cochlear width; (3) number of turns of cochlear canal; (4) 144 cochlear volume; (5) cochlear canal length; (6) length of secondary spiral lamina (SSL); (7) 145 basal ratio (cochlear height/cochlear width); (8) axial pitch (cochlear height/number of turns); 146 and (9) percentage of extent of secondary spiral lamina ((secondary spiral lamina 147 length/cochlear canal length)*100). We also measured (10) width of basal turn perpendicular to 148 cochlear width (W2); (11) maximum distance between turns of the cochlea (ITD); and (12) area 149 of fenestra cochlearis (FC) following Churchill et al. (2016). Where possible $(n=7)$ for the 150 specimens of $P$. phocoena, we also collected condylobasal length (skull length in $\mathrm{mm}$ ) as a 151 proxy for body size as body mass data was not available for all specimens. 
153 We chose these measurements because they relate to auditory function in cetaceans. Cochlear

154 height $(1)$ and width $(2,10)$ relate to the auditory abilities of odontocetes (West, 1985; Ketten \&

155 Wartzok, 1990). The number of turns of the cochlear canal (3) also relates to auditory abilities

156 and differs among mammal groups (West, 1985; Ketten \& Wartzok, 1990; Ekdale \& Rowe,

157 2011). Cochlear volume (4) is used as an estimate of size which relates to body mass and

158 length (Racicot et al., 2016). Cochlear canal length (5) correlates with body size in odontocetes

159 and is used as a quantitative measurement for comparison (Ketten, 1992a). Length of

160 secondary spiral lamina (6) was measured to calculate percentage of extent of secondary spiral

161 lamina (9), an indicator of the stiffness of the basilar membrane that is associated with high

162 frequency hearing (Ekdale \& Racicot, 2015; Park et al., 2017a). Basal ratio (7) and axial pitch

163 (8) are two quantitative ways to examine cochlear shape and size for comparative studies

164 (Racicot et al., 2016). Both measurements are negatively correlated with frequency of hearing

165 (Ketten \& Wartzok, 1990). Taxa that use high frequency hearing also tend to have a larger inter-

166 turn distance (11; Ekdale \& Racicot, 2015). The area of the fenestra cochleae (12) tends to be

167 larger in low frequency species, although beaked whales and sperm whales also have large 168 areas.

169

170 We then performed a principal component analysis (PCA) on the scaled and centred linear

171 measurements listed above using the 'prcomp' function in R; and used these principal

172 components (PCs) in further analyses.

173

174 All data used in this study are available on the NHM Data Portal (data.nhm.ac.uk). The 3D

175 shape data for cochleae of $P$. phocoena, linear measurements of all cochleae, and other data

176 used in this paper are deposited in Martins, Park \& Cooper (2019). 3D shape data for cochleae

177 of other odontocetes were collected for Park et al. (2019) and are deposited in Park et al.

178 (2018).

Peer) reviewing PDF | (2019:08:40803:2:0:CHECK 5 Mar 2020) 
182 All analyses were carried out in $\mathrm{R}$ version 3.4.3 (R Core Team, 2019), and reproducible $\mathrm{R}$ 183 scripts are available on GitHub (github.com/nhcooper123/intraspecific-porpoise; Cooper, 184 Martins \& Park, 2020).

Quantifying intraspecific variation in Phocoena phocoena

187 To quantify intraspecific variation in cochleae of $P$. phocoena we estimated disparity for all 188 principal components of the 3D shape data and linear measurements separately, using the $R$ 189 package dispRity (Guillerme, 2018). We used the sum of variances and median centroid 190 distance metrics as our disparity metrics. For each linear measurement we also calculated the coefficient of variation (CV), i.e. (standard deviation/mean)*100. Generally values of CV below $30 \%$ represent low levels of variation (Brown, 1998), and previous studies that found low levels of intraspecific variation in cochleae find values of CV below 20\% (Ekdale \& Rowe, 2011; Mennecart \& Costeur, 2016; Racicot, Darroch \& Kohno, 2018). We also calculated values of CV for our measurements using data from previous studies of cochleae intraspecific variation in odontocetes so we could compare the values to those of $P$. phocoena. Where these studies contained right and left cochleae from one individual we first took the mean for the individual, then calculated CV across individuals.

199

Comparing intraspecific variation and interspecific variation

201 Quantifying the amount of intraspecific variation alone does not tell us whether intraspecific 202 variation may confound the results of studies of interspecific variation. To investigate this we 203 tested whether there were significantly higher levels of variation in cochlear shape among $P$. 204 phocoena and the other odontocetes than within the specimens of $P$. phocoena. For the 3D 
205 shape data, we first conducted a Procrustes MANOVA (multivariate analysis of variance) using 206 the 'proc.Im' function from GEOMORPH using the Procrustes aligned coordinates as the 207 response variable, and the grouping variable ( $P$. phocoena vs. other odontocetes) as the 208 explanatory variable. Next we fitted a standard MANOVA using the 'manova' function in R, with 209 the first 26 PC axes scores (comprising $95 \%$ of the variance in cochlear shape) as the response 210 variable. To identify which PCs, if any, were most important in driving any differences among 211 the cochleae of $P$. phocoena and other odontocetes we also used analysis of variance (ANOVA) 212 to test each PC separately. To account for multiple testing we Bonferroni corrected our $p$ values. 213 Finally, we repeated the latter two analyses, i.e. MANOVA and ANOVAs, using the first six PC 214 axes (comprising 95\% of the variance) extracted from the linear measurements.

216 We visualised specimen position in 2D morphospace across combinations of PCs 1,2 , and 3 217 (3D shape data) and PCs 1-4 (linear measurement data) as these PCs were significant in our 218 ANOVAs (see Results). To aid the interpretation of our results we also created morphospace 219 plots of PC1 and PC2 where species were coloured based on taxonomic family and a selection 220 of ecological variables; specifically habitat (riverine $=>50 \%$ of time spent in river, nearshore $=>$ $22150 \%$ of time spent in coastal waters, oceanic $=>50 \%$ of time spent in pelagic waters), diet 222 (generalist $=$ consumes a wide variety of prey types, fish $=>50 \%$ of diet is fish, cephalopods $=$ $223>50 \%$ of diet is cephalopods), feeding mode (raptorial = prey capture occurs mainly via 224 snapping or ram feeding, suction = prey capture occurs mainly via suction, i.e. obligate suction 225 feeders), and dive type (shallow = maximum estimated dive depth less than 100m; middle depth 226 = maximum estimated dive depth $\sim 500 \mathrm{~m}$; deep = maximum estimated dive depth $\sim 1000 \mathrm{~m}$; very 227 deep = maximum estimated dive depth greater than $1000 \mathrm{~m})$ and hearing type $(\mathrm{NBHF}=$ known 228 or presumed to use narrow band high-frequency sonar; Type $2=$ do not use NBHF). Some taxa 229 fall into several of these categories so we assigned these to composite categories e.g. Tursiops 
230 is classed as nearshore/oceanic. Details of the categories for each species, and the references

231 these were taken from, are in Tables S4 and S5. We also tested whether these variables were 232 correlated with overall cochlear shape using MANOVAs.

233

234 Sensitivity analyses

235 Because we have 18 specimens of $P$. phocoena and only one specimen of each of the other 236 species, cochleae of $P$. phocoena will have a stronger effect on the principal components 237 scores than other cochleae, distorting the morphospace. Ideally we would collate an equal 238 number of cochleae for each species, but these specimens simply do not exist in these numbers 239 for the majority of species. Specimens of $P$. phocoena are the most readily available because 240 they are common and often strand (Coombs et al., 2019). Their skulls are also small enough to 241 store in bulk within natural history collections. To determine whether this distortion problem 242 influenced our conclusions, we sampled two specimens of $P$. phocoena from the 18 and then 243 repeated the GPA, PCA, and MANOVA analyses described above for the 3D shape dataset. 244 We repeated this for every possible combination of two specimens of $P$. phocoena, and then for 245 every combination of three specimens and so on until reaching every combination of 17 246 specimens.

248 To determine whether our results apply only to broad-scale taxonomic comparisons, i.e.

249 P. phocoena vs. other odontocetes, we also repeated our GPA, PCA and MANOVA analyses 250 comparing P. phocoena with other species of Phocoena only (P.dioptrica, P.sinus, 251 P.spinipinnis). 3D shape analyses used PC1 - PC14, and linear measurement analyses used 252 PC1 - PC7 as these were the PCs required to account for 95\% of the variation in cochlear 253 shape in each case. 
255 Finally, variation within cochleae of $P$. phocoena may be explained by the differences among 256 the specimens (Table S3) in terms of whether the cochleae came from the left or right side of 257 the animal, their sex, origin or body size. We therefore tested whether variation in cochleae of $P$. 258 phocoena was significantly correlated with the side of the head the cochlea came from, or the 259 sex, origin (UK vs. USA) or skull length (as a proxy for body size) of the specimens. We 260 repeated our GPA and PCA analyses for the specimens of $P$. phocoena only, and then used the 261 resulting Procrustes coordinates or PCs as response variables in Procrustes ANOVAs or 262 MANOVAs with either side, sex, origin or log skull length as predictors. 3D shape analyses used 263 PC1 - PC16, and linear measurement analyses used PC1 - PC7 as these were the PCs 264 required to account for $95 \%$ of the variation in cochlear shape in each case. For 3D shape 265 analyses where sex or skull length were the predictors we used only PC1 - PC6 (accounting for $26675 \%$ of the variation on cochlear shape) because there were not enough observations to fit 267 MANOVAs for all 16 PCs.

268

269

Results

270

$2713 D$ shape variation

272 The first 26 principal components (PC) axes comprised 95\% of the variance in cochlear shape. 273 PC1 accounted for $34.08 \%$ of the cochlear shape variation (Figure 3), and represents cochleae 274 that are positively correlated with having a less oval-shaped and more circular fenestra vestibuli. 275 PC2 accounted for $12.15 \%$ of the shape variation and represents cochleae that are negatively 276 correlated with having a radial expansion of the scala tympani (i.e. a tympanal recess, sensu 277 Park et al., 2017b; Park, Fitzgerald \& Evans, 2017c; Figure 3), and PC3 accounted for 8.956\% 278 of the shape variation (Figure 3), and represents cochleae that are positively correlated with 279 having cochlear canals that do not overlap the basal turn. 
281

282 283

284

285

286

287

288

289

290

291

292

293

294

295

296

297

298

299

300

301

302

303

304

Linear measurements

The first six PC axes comprised $95 \%$ of the variance in cochlear linear measurements. PC1 accounted for $54.28 \%$ of the variation (Figure 4), which is best described by a combination of cochlea width, W2, ITD and cochlea height. PC2 accounted for $18.65 \%$ of the variation best described by basal ratio and extent of secondary spiral lamina (Figure 4). PC3 (8.579\% of the variation) and PC4 (6.355\% of the variation) are best described by secondary spiral lamina extent and number of turns respectively (Figure 4).

\section{Quantifying intraspecific variation in Phocoena phocoena}

The disparity of $P$. phocoena in the 3D shape data (sum of variances $=0.014$, median centroid distance $=0.100$ ) is lower than in the linear measurement data (sum of variances $=1.487$, median centroid distance $=1.091)$, although the morphospace occupied is larger compared with other odontocetes in the 3D shape data (Figures 3 and 4). Values of CV vary across the linear measurements (Table 1) but all are below $30 \%$ and only area of fenestra cochlearis (FC) exceeds $20 \%$. This reflects low levels of intraspecific variation in cochleae of $P$. phocoena. Values of CV for all measurements except cochlear volume, axial pitch and ITD are higher than those found in previous studies (Table 1; Table S6).

\section{Comparing intraspecific variation and interspecific variation}

There was significantly more variation among odontocete species than within the specimens of P. phocoena (Table 2; Figures 3 and 4 ) when the entire shape of the cochlea was considered, whether we used Procrustes coordinates or PCs from the 3D shape data or linear measurements. 
305 When we investigated individual PC axes (Table S7), for the 3D shape data we found that only 306 PC1 and PC3 of the 26 PCs significantly differed between P. phocoena and other odontocetes, 307 and for linear measurements only PC1, PC2 and PC4 (only PC1 and PC2 are significant after 308 Bonferroni correction) showed significant differences among the two groups.

309

310 Figures S1 and S2 show how species are spread across PC1/PC2 morphospace according to 311 taxonomic family, habitat, diet, feeding mode, dive type and hearing type. All of these variables 312 except feeding mode were also significantly correlated with cochlear shape (Table S8).

314 Sensitivity analyses

315 In our sensitivity analyses, MANOVAs for 3D shape data remained significant provided at least 316 four specimens of $P$. phocoena were included in the analyses (Figures S3 and S4).

318 When the specimens of $P$. phocoena were compared to other Phocoena species only, there was still significantly less variation within the specimens of $P$. phocoena using Procrustes coordinates from the 3D shape data (but not for PCs) and linear measurements (Table S9).

Variation in cochleae of $P$. phocoena was not significantly correlated with the side of the head the cochlea came from, the sex, or skull length of the specimens for either 3D shape data or linear measurements (Table S10). Origin (UK vs. USA) was not significantly correlated with variation in cochleae of $P$. phocoena for the linear measurements, but was significantly correlated with variation in the 3D shape data $(p=0.038$; after Bonferroni correction $p=0.152)$.

327 This is driven by the large negative value of PC1 for the USA specimen. To ensure this did not 328 influence our intraspecific variation results (see above) we repeated our 3D shape analyses 329 (including the GPA and PCA steps) removing this specimen (NHMUK_1873.6.3.45). The results 330 are qualitatively identical to those including the USA specimen (Table S11). 


\section{Discussion}

333

334 In this study, we tested whether intraspecific variation is a major confounding factor in cross-

335 species analyses by comparing variation within the cochleae of the harbour porpoise (Phocoena

336 phocoena) with those across a broad sample of other odontocete species. Levels of

337 intraspecific variation in cochleae of $P$. phocoena were lower than the levels of variation seen

338 across other odontocetes. P. phocoena showed higher values of coefficient of variation (CV)

339 overall (ranging from 3.394 - 26.80\%; Table 1) compared to other odontocetes (ranging from 0 -

$34023.33 \%$; Table S6), however, for most cochlear measurements the values of CV were similar.

341 The greatest difference in values of $\mathrm{CV}$ was for the fenestra cochlearis, which may be artificially

342 variable due to a lack of standardised protocol for measuring it (Racicot et al., 2016; Churchill et

343 al., 2016). Intraspecific variation in $P$. phocoena might be expected to be higher than in other

344 odontocetes because of their large geographic range which stretches across almost all shallow

345 cool temperate to subpolar waters of the northern hemisphere, within which they encounter

346 many different kinds of habitats (Jefferson, 2014). This suggests that $P$. phocoena should

347 generally have a higher level of intraspecific variation compared to other odontocetes with more

348 limited geographic ranges and habitats. We cannot test this here, due to the paucity of studies

349 containing more than one specimen for each species, but future research should compare the

350 values of $\mathrm{CV}$ found for $P$. phocoena here with those of another similarly widespread species, for

351 example Tursiops truncatus (common bottlenose dolphin) or Delphinus delphis (short-beaked

352 common dolphin).

353

354 Although there was significantly more variation among odontocete species than among the

355 specimens of $P$. phocoena, for at least some principal components, specimens from other

356 species overlapped with $P$. phocoena. Cochlear morphology was also related to habitat, diet, 
357 mode of echolocation, and dive type (Table S8), suggesting that species identity alone is not

358 enough to explain variation across all principal components. In addition, not all of the specimens

359 of $P$. phocoena cluster together tightly (Figure 3). This could reflect differences in cochlear

360 morphology among populations (although this does not appear to be the case for these data as

361 only one specimen is from the USA and the rest are from the UK), or variability within the

362 species. Cochleae also exhibit convergent evolution (Park et al., 2019), so individuals or

363 species that live in similar acoustic environments (regions where variables such as water

364 temperature, pressure, and salinity result in sound travelling through the water at similar

365 velocities) as $P$. phocoena may have similar cochleae. The relatively low levels of intraspecific

366 variation found in $P$. phocoena adds further support for the acoustic environment being a

367 constraint on cochlear morphology. This is additionally demonstrated in the morphospace plot of

368 PC1 and PC2 (Figure 3), the area occupied by $P$. phocoena is shared with taxa such as $P$.

369 sinus (vaquita), Cephalorhynchus commersonii (Commerson's dolphin), and Inia geoffrensis

370 (Amazon river dolphin), all of which also live in shallow waters. However, other taxa that spend

371 more time in deeper waters, for example Pseudorca crassidens (false killer whale) and Tursiops

372 truncatus, also occupy this region of morphospace, indicating that additional factors are also in

373 play, although they may also frequent shallower waters or have coastal ecotypes (Jefferson,

374 Webber \& Pitman, 2015). Previous studies have also suggested that constraints on cochlear

375 morphology are strong, due to several factors including frequency propagation (Manoussaki et

376 al., 2008), spatial constraints (Pietsch et al., 2017), and its vital importance for survival in

377 odontocetes (Ketten,1992a). As such the capacity for elaboration or innovation in cochlear

378 shape may be limited, which could force all odontocete cochleae to fall within the same limited

379 morphospace. Other sources of error, such as mislabelling of specimens in collections or errors

380 in $\mu$ CT scanning or landmarking, are unlikely due to the care taken during these stages, and

381 assistance from expert curators in museum collections. 
383 Although, as described above, the specimens of $P$. phocoena did not cluster together closely in 384 our PC plots, we note that PC plots only show two dimensions of the data, not all of the 26 PC 385 axes that comprised $95 \%$ of the variance in cochlear shape. Our MANOVA results, however, 386 showed that there was significantly more variation in cochlear shape among odontocete species 387 than within P. phocoena specimens. This highlights that clustering (or not) in several PC axes, 388 does not necessarily equate to clustering across the entire morphospace, although limitations in 389 how we visualise more than three dimensions mean that PC plots are still valuable visualisation 390 tools. In addition, although PCAs on different datasets are not directly comparable, shape 391 variation in the cochleae of odontocetes appears to be spread across a much higher number of 392 PCs than that seen in most studies involving skulls (e.g. Cardini \& Polly, 2013; McCurry et al., 393 2017; Page \& Cooper 2017; Randau, Sanfelice \& Goswami, 2019).

Conclusion

396

397 The 18 specimens of $P$. phocoena used in this study represent the highest number of records 398 for one species used in intraspecific studies of cochlear morphology (the next highest is 12 399 individual sperm whales; Schnitzler et al., 2017) in cetaceans. Overall, our results show that 400 intraspecific variation of cochlea shape in $P$. phocoena is lower than interspecific variation of 401 cochlea shape across odontocetes. Assuming that interspecific variation of $P$. phocoena is representative of patterns across odontocetes, this suggests we can still be reasonably confident in our conclusions when using $n=1$ for comparative studies of cochlea morphology,

404 as done in most previous studies (Ekdale \& Racicot, 2015; Ekdale, 2016; Park, Fitzgerald \& 405 Evans, 2016; Park et al., 2017a; Park et al., 2017b). It is possible that $P$. phocoena is not 406 representative of patterns across odontocetes. If $P$. phocoena is less variable than other 407 odontocetes this would reduce our confidence that using just one specimen for comparative 408 studies is sufficient. However, as discussed above, we believe this is unlikely because $P$. 
409 phocoena has a broad geographic range, and shows variability in habitat use and trophic 410 ecology across that range (Bjørge 2003; Jefferson 2014). As such we speculate that $P$.

411 phocoena is instead likely to be more variable than most species making our conclusions more 412 conservative. Ideally, future studies should use multiple cochleae for each species, but where 413 this is impossible due to the rarity of specimens, or expense of specimen loans and/or $\mu \mathrm{CT}$ 414 scanning, this should not influence the conclusions of comparative studies, assuming results 415 from P.phocoena can be generalised across odontocetes. 
416

417

418

419

420

421

422

423

424

425

426

427

428

429

430

431

432

433

434

435

436

437

438

439

440

\section{References}

Adams, D.C., Rohlf, F.J. and Slice, D.E., 2013. A field comes of age: geometric morphometrics in the 21st century. Hystrix, 24(1), 7.

Adams, D.C., Collyer, M.L. and Kaliontzopoulou, A., 2018. Geomorph: Software for geometric morphometric analyses. $\mathrm{R}$ package version 3.0.6.

Benoit, J., Lehmann, T., Vatter, M., Lebrun, R., Merigeaud, S., Costeur, L. and Tabuce, R., 2015. Comparative anatomy and three-dimensional geometric-morphometric study of the bony labyrinth of Bibymalagasia (Mammalia, Afrotheria). Journal of Vertebrate Paleontology, 35(3), e930043.

Billet, G., Hautier, L. and Lebrun, R., 2015. Morphological diversity of the bony labyrinth (inner ear) in extant xenarthrans and its relation to phylogeny. Journal of Mammalogy, 96(4), 658-672.

Bolnick, D.I., Amarasekare, P., Araújo, M.S., Bürger, R., Levine, J.M., Novak, M., Rudolf, V.H., Schreiber, S.J., Urban, M.C. and Vasseur, D.A., 2011. Why intraspecific trait variation matters in community ecology. Trends in Ecology \& Evolution, 26(4), 183-192.

Bookstein, F., Schäfer, K., Prossinger, H., Seidler, H., Fieder, M., Stringer, C., Weber, G.W., Arsuaga, J.L., Slice, D.E., Rohlf, F.J. and Recheis, W., 1999. Comparing frontal cranial profiles in archaic and modern Homo by morphometric analysis. The Anatomical Record: An Official Publication of the American Association of Anatomists, 257(6), 217-222. 
441 Bjørge, A. 2003. The harbour porpoise (Phocoena phocoena) in the North Atlantic: Variability in 442 habitat use, trophic ecology and contaminant exposure. NAMMCO Scientific Publications, 5, 443 223-228.

444

445 Brown, C.E., 2012. Applied multivariate statistics in geohydrology and related sciences.

446 Springer Science \& Business Media.

447

448 Cantos, R., Cole, L.K., Acampora, D., Simeone, A. and Wu, D.K., 2000. Patterning of the 449 mammalian cochlea. Proceedings of the National Academy of Sciences, 97(22), 11707-11713. 450

451 Cardini, A. and Polly, P.D., 2013. Larger mammals have longer faces because of size-related 452 constraints on skull form. Nature Communications, 4, 2458.

453

454 Churchill, M., Martinez-Caceres, M., de Muizon, C., Mnieckowski, J. and Geisler, J.H., 2016.

455 The origin of high-frequency hearing in whales. Current Biology, 26(16), 2144-2149.

456

457 Coombs, E. J., Deaville, R., Sabin, R. C., Allan, L., O'Connell, M., Berrow, S., Smith, B., 458 Brownlow, A., Doeschate, M.T., Penrose, R., Williams, R., Perkins, M.W., Jepson, P.D. and 459 Cooper, N., 2019. What can cetacean stranding records tell us? A study of UK and Irish 460 cetacean diversity over the past 100 years. Marine Mammal Science, 35, 1527-1555.

461

462 Cooper, N., Martins, M.C.I., and Park, T., 2020. GitHub: nhcooper123/intraspecific-porpoise: 463 code for the paper. Zenodo. DOI: 10.5281/zenodo.3693950. 
465 Costeur, L., Grohé, C., Aguirre-Fernández, G., Ekdale, E., Schulz, G., Müller, B. and

466 Mennecart, B., 2018. The bony labyrinth of toothed whales reflects both phylogeny and habitat 467 preferences. Scientific Reports, 8(1), 7841.

468

469 Des Roches, S., Post, D.M., Turley, N.E., Bailey, J.K., Hendry, A.P., Kinnison, M.T., Schweitzer, 470 J.A. and Palkovacs, E.P., 2018. The ecological importance of intraspecific variation. Nature

471 Ecology \& Evolution, 2(1), 57.

472

473 Ekdale, E.G., 2010. Ontogenetic variation in the bony labyrinth Monodelphis domestica 474 (Mammalia: Marsupialia) following ossification of the inner ear cavities. The Anatomical Record:

475 Advances in Integrative Anatomy and Evolutionary Biology, 293(11), 1896-1912.

476

477 Ekdale, E.G. and Rowe, T., 2011. Morphology and variation within the bony labyrinth of 478 zhelestids (Mammalia, Eutheria) and other therian mammals. Journal of Vertebrate 479 Paleontology, 31(3), 658-675.

480

481 Ekdale, E.G., 2013. Comparative anatomy of the bony labyrinth (inner ear) of placental 482 mammals. PLoS One, 8(6), e66624.

483

484 Ekdale, E.G. and Racicot, R.A., 2015. Anatomical evidence for low frequency sensitivity in an 485 archaeocete whale: comparison of the inner ear of Zygorhiza kochii with that of crown Mysticeti. 486 Journal of Anatomy, 226(1), 22-39.

487

488 Ekdale, E.G., 2016. Morphological variation among the inner ears of extinct and extant 489 baleen whales (Cetacea: Mysticeti). Journal of Morphology, 277(12), 1599-1615. 
491 Galatius, A., Olsen, M.T., Steeman, M.E., Racicot, R.A., Bradshaw, C.D., Kyhn, L.A. and Miller, 492 L.A., 2019. Raising your voice: evolution of narrow-band high-frequency signals in toothed 493 whales (Odontoceti). Biological Journal of the Linnaean Society, 126(2), 213-224.

495 Gonzales, L.A., Malinzak, M.D. and Kay, R.F., 2019. Intraspecific variation in semicircular canal 496 morphology - A missing element in adaptive scenarios? American Journal of Physical 497 Anthropology, 168(1), 10-24.

498

499 Guillerme, T., 2018. dispRity: a modular R package for measuring disparity. Methods in Ecology 500 and Evolution, 9(7), 1755-1763.

501

502 Gunz, P., Mitteroecker, P. and Bookstein, F.L., 2005. Semilandmarks in three dimensions. In 503 Modern Morphometrics in Physical Anthropology (pp. 73-98). Springer: Boston, MA.

504

505 Hocking DP, Marx FG, Park T, Fitzgerald EMG, Evans AR. 2017. A behavioural

506 framework for the evolution of feeding in predatory aquatic mammals. Proceedings of the

507 Royal Society B: Biological Sciences. 284, 20162750.

508

509 Hocking DP, Marx FG, Park T, Fitzgerald EMG, Evans AR. 2017. Reply to comment 510 by Kienle et al. 2017. Proceedings of the Royal Society B: Biological Sciences. 284, 51120171836.

513 Ishikawa, K., Onoda, Y. and Hikosaka, K., 2007. Intraspecific variation in temperature 514 dependence of gas exchange characteristics among Plantago asiatica ecotypes from different 515 temperature regimes. New Phytologist, 176(2), 356-364. 
517 Jefferson, T.A., 2014. Family Phocoenidae (Porpoises). In Wilson D.E., Mittermeier R.A. eds.

518 Handbook of the Mammals of the World. Vol 4. Sea Mammals (pp. 528-547). Lynx Edicions, 519 Barcelona.

520

521 Jefferson T.A., Webber M.A., and Pitman R.L. 2015. Marine mammals of the world: $A$

522 Comprehensive guide to their identification (second edition) (pp. 326-329). Academic Press, 523 London.

524

525 Ketten, D.R. and Wartzok, D., 1990. Three-dimensional reconstructions of the dolphin ear. In 526 Sensory Abilities of Cetaceans (pp. 81-105). Springer, Boston, MA.

527

528 Ketten, D.R., 1992a. The cetacean ear: form, frequency, and evolution. In Marine Mammal 529 Sensory Systems (pp. 53-75). Springer, Boston, MA.

530

531 Ketten, D.R., 1992b. The marine mammal ear: specializations for aquatic audition and 532 echolocation. In The Evolutionary Biology of Hearing (pp. 717-750). Springer, New York, NY. 533

534 Luo, Z. and Marsh, K., 1996. Petrosal (periotic) and inner ear of a Pliocene kogiine whale 535 (Kogiinae, Odontoceti): implications on relationships and hearing evolution of toothed whales. 536 Journal of Vertebrate Paleontology, 16(2), 328-348.

537

538 Marx, F.G., Park, T., Fitzgerald, E.M. and Evans, A.R., 2018. A Miocene pygmy right whale 539 fossil from Australia. PeerJ, 6, e5025. 
541 McCurry, M.R., Evans, A.R., Fitzgerald, E.M., Adams, J.W., Clausen, P.D. and McHenry, C.R.,

542 2017. The remarkable convergence of skull shape in crocodilians and toothed whales.

543 Proceedings of the Royal Society B: Biological Sciences, 284(1850), 20162348.

544

545 Manoussaki, D., Chadwick, R.S., Ketten D.R., Arruda, J., Dimitriadis, E.K. and O'Malley, J.T., 546 2008. The influence of cochlear shape on low-frequency hearing. Proceedings of the National 547 Academy of Sciences, 105 (16), 6162-6166.

548

549 Martins, M.C.I., Park, T. and Cooper, N., 2019. Dataset: Intraspecific variation in harbour 550 porpoise cochleae. Natural History Museum Data Portal (data.nhm.ac.uk).

551 https://doi.org/10.5519/0091362.

552

553

Mennecart, B. and Costeur, L., 2016. Shape variation and ontogeny of the ruminant bony

554 labyrinth, an example in Tragulidae. Journal of Anatomy, 229(3), 422-435.

555

556 Mourlam, M.J. and Orliac, M.J., 2017. Infrasonic and ultrasonic hearing evolved after the 557 emergence of modern whales. Current Biology, 27(12), 1776-1781.

558

559 O'Dell, R.E. and Rajakaruna, N., 2011. Intraspecific variation, adaptation, and evolution. In 560 Serpentine: Evolution and Ecology in a Model System (pp. 97-137). University of California 561 Press, Berkeley.

562

563 Page, C.E. and Cooper, N., 2017. Morphological convergence in 'river dolphin' skulls. PeerJ, 5, 564 e4090. 
566 Park, T., Fitzgerald, E.M. and Evans, A.R., 2016. Ultrasonic hearing and echolocation in the 567 earliest toothed whales. Biology Letters, 12(4), 20160060.

568

569 Park, T., Marx, F.G., Fitzgerald, E.M. and Evans, A.R., 2017a. The cochlea of the enigmatic 570 pygmy right whale Caperea marginata informs mysticete phylogeny. Journal of Morphology, $571278(6), 801-809$.

572

573 Park, T., Evans, A. R., Gallagher, S. J. and Fitzgerald, E. M., 2017b. Low-frequency hearing 574 preceded the evolution of giant body size and filter feeding in baleen whales. Proceedings of the 575 Royal Society B: Biological Sciences, 284, 20162528.

576

577 Park, T., Fitzgerald, E.M. and Evans, A.R., 2017c. The tympanal recess of the cetacean 578 cochlea: Function and evolution. Acoustics Australia, 45(2), 273-278.

579

580

Park, T., Mennecart, B., Costeur, L., Grohé, C. and Cooper, N., 2018. Dataset: Convergent 581 evolution in toothed whale cochleae. Natural History Museum Data Portal (data.nhm.ac.uk). 582 https://doi.org/10.5519/0082968.

583

584 Park, T., Mennecart, B., Costeur, L., Grohé. and Cooper, N., 2019. Convergent evolution in 585 toothed whale cochleae. BMC Evolutionary Biology, 9, 195.

586

587 Pietsch, M., Dávila, L.A., Erfurt, P., Avci, E., Lenarz, T. and Kral, A., 2017. Spiral form of the 588 human cochlea results from spatial constraints. Scientific Reports, 7(1), 7500.

589

590 R Core Team, 2019. R: A language and environment for statistical computing. R Foundation for 591 Statistical Computing, Vienna, Austria. http://www.R-project.org/. 
592

593 Racicot, R.A., Gearty, W., Kohno, N. and Flynn, J.J., 2016. Comparative anatomy of the bony

594 labyrinth of extant and extinct porpoises (Cetacea: Phocoenidae). Biological Journal of the

595 Linnean Society, 119(4), 831-846.

596

597 Racicot, R.A., Darroch, S.A. and Kohno, N., 2018. Neuroanatomy and inner ear labyrinths of the 598 narwhal, Monodon monoceros, and beluga, Delphinapterus leucas (Cetacea: Monodontidae).

599 Journal of Anatomy, 233(4), 421-439.

600

601 Racicot, R.A., Boessenecker, R.W., Darroch, S.A. and Geisler,J.H., 2019. Evidence for

602 convergent evolution of ultrasonic hearing in toothed whales (Cetacea: Odontoceti). Biology

603 Letters, 15(5), 20190083.

604

605 Randau, M., Sanfelice, D. and Goswami, A., 2019. Shifts in cranial integration associated with

606 ecological specialization in pinnipeds (Mammalia, Carnivora). Royal Society Open Science,

607 6(3), 190201.

608

609 Schnitzler, J.G., Frédérich, B., Früchtnicht, S., Schaffeld, T., Baltzer, J., Ruser, A. and Siebert,

610 U., 2017. Size and shape variations of the bony components of sperm whale cochleae.

611 Scientific Reports, 7, 46734.

612

613 Thean, T., Kardjilov, N. and Asher, R.J., 2017. Inner ear development in cetaceans. Journal of

614 Anatomy, 230(2), 249-261.

615

616 Visualization Sciences Group-a FEI Company, 2016. Avizo: 3D analysis software for scientific 617 and industrial data, standard edition. 
618

619 West, C.D., 1985. The relationship of the spiral turns of the cochlea and the length of the basilar 620 membrane to the range of audible frequencies in ground dwelling mammals. The Journal of the 621 Acoustical Society of America, 77(3), 1091-1101.

622

623 Wiley, 2005. Landmark Editor 3.0. Institute for Data Analysis and Visualization.

624

625 3D Systems, 2017. Geomagic Wrap.

626

627

\section{Acknowledgements}

629 We thank: Oliver Lambert (IRNSB), Gabriel Aguirre Fernandez (UZH), Brett Clark and Vincent 630 Fernandez (NHM), Alistair Evans (MU) and Loïc Costeur (UB) for scanning several of the 631 specimens in this study; Richard Sabin and Roberto Portela Miguez (NHM), Erich Fitzgerald 632 and Karen Roberts (NMV), Neil Duncan and Eileen Westwig (AMNH) for access to specimens.

633

634

635

Data and code availability

636 All data are available on the NHM Data Portal (data.nhm.ac.uk). 3D data for cochleae of $P$. 637 phocoena, linear measurements of all cochleae, and other data used in this paper are in 638 Martins, Park \& Cooper (2019; doi.org/10.5519/0091362). 3D data for cochleae of the other 639 odontocete species are available from Park et al. (2018; doi.org/10.5519/0082968).

640 Reproducible R scripts are available on GitHub (github.com/nhcooper123/intraspecific-porpoise;

641 Cooper, Martins \& Park, 2020). 


\section{Table $\mathbf{1}$ (on next page)}

[i]Table 1: Coefficients of variation (CV) of 12 linear measurements for 18 Phocoena phocoena specimens, along with the mean $\mathrm{CV}$ of these measurements from previous odontocete studies (see Table S3 for raw data), the number of studies featuring each measur

$S S L=$ length of secondary spiral lamina; W2 $=$ Width of basal turn perpendicular to cochlear width; ITD = Inter-turn distance, maximum distance between turns; FC = area of fenestra cochlearis (FC). No previous studies measured intraspecific variation in SSL or extent of SSL. 
1 Table 1: Coefficients of variation (CV) of 12 linear measurements for 18 Phocoena

2 phocoena specimens, along with the mean CV of these measurements from previous

3 odontocete studies (see Table S3 for raw data), the number of studies featuring each

4 measurement $(N)$, and the maximum number of individuals in each of these previous

5 studies. SSL = length of secondary spiral lamina; $W 2=$ Width of basal turn

6 perpendicular to cochlear width; ITD = Inter-turn distance, maximum distance between

7 turns; $F C=$ area of fenestra cochlearis $(F C)$. No previous studies measured intraspecific

8 variation in SSL or extent of SSL.

\begin{tabular}{|l|l|l|l|l|}
\hline & This & \multicolumn{3}{|l|}{ Previous studies } \\
\hline measurement & CV (\%) & $\begin{array}{l}\text { Mean CV } \\
(\%)\end{array}$ & N & $\begin{array}{l}\text { maximum } \\
\text { number of } \\
\text { individuals }\end{array}$ \\
\hline cochlea height & 7.783 & 6.793 & 8 & 12 \\
\hline cochlea width & 4.842 & 3.364 & 4 & 12 \\
\hline number of turns of the & 3.394 & 2.478 & 7 & 5 \\
\hline cochlear canal & 8.015 & 10.23 & 1 & 2 \\
\hline cochlear volume & 6.189 & 3.401 & 4 & 12 \\
\hline cochlear canal length & 6.619 & - & - & - \\
\hline SSL & 8.846 & 0.000 & 1 & 2 \\
\hline basal ratio & 8.688 & 8.736 & 5 & 4 \\
\hline axial pitch & & & & \\
\hline
\end{tabular}




\begin{tabular}{|l|l|l|l|l|}
\hline extent of SSL & 3.089 & - & - & - \\
\hline W2 & 7.612 & 2.544 & 2 & 5 \\
\hline ITD & 11.93 & 12.622 & 2 & 5 \\
\hline FC & 26.80 & 9.838 & 2 & 5 \\
\hline
\end{tabular}

9 


\section{Table 2 (on next page)}

Table 2. Results of Procrustes MANOVA and standard MANOVA analyses using either Procrustes aligned coordinates [i]or principal components (PCS) accounting for $95 \%$ of the variance as the response variable, and whether a specimen was Phocoena phocoena

3D shape data analyses used PCs 1 to 26; linear measurements analyses used PCs 1 to 6 . 
1 Table 2. Results of Procrustes MANOVA and standard MANOVA analyses using either

2 Procrustes aligned coordinates or principal components (PCs) accounting for $95 \%$ of

3 the variance as the response variable, and whether a specimen was Phocoena

4 phocoena or another odontocete species as the explanatory variable. 3D shape data

5 analyses used PCs 1 to 26; linear measurements analyses used PCs 1 to 6.

\begin{tabular}{|c|c|c|c|c|}
\hline \multicolumn{5}{|c|}{ 3D shape data } \\
\hline test & df & Flapprox F & Pillai & $\mathbf{p}$ \\
\hline $\begin{array}{l}\text { Procrustes } \\
\text { ANOVA }\end{array}$ & 1,67 & 6.005 & NA & 0.001 \\
\hline MANOVA & 1,67 & 8.623 & 0.842 & $<0.001$ \\
\hline \multicolumn{5}{|c|}{ Linear measurements } \\
\hline MANOVA & 1,67 & 9.090 & 0.468 & $<0.001$ \\
\hline
\end{tabular}

6

7

8 
Figure 1

Endocast of NHMUK_SW1934.31 in anterior, lateral, dorsal and ventral views showing semi-landmark curves.

A-anterior view, B-lateral view, C-dorsal view, D-ventral view. Dotted lines show the semilandmark curves. 


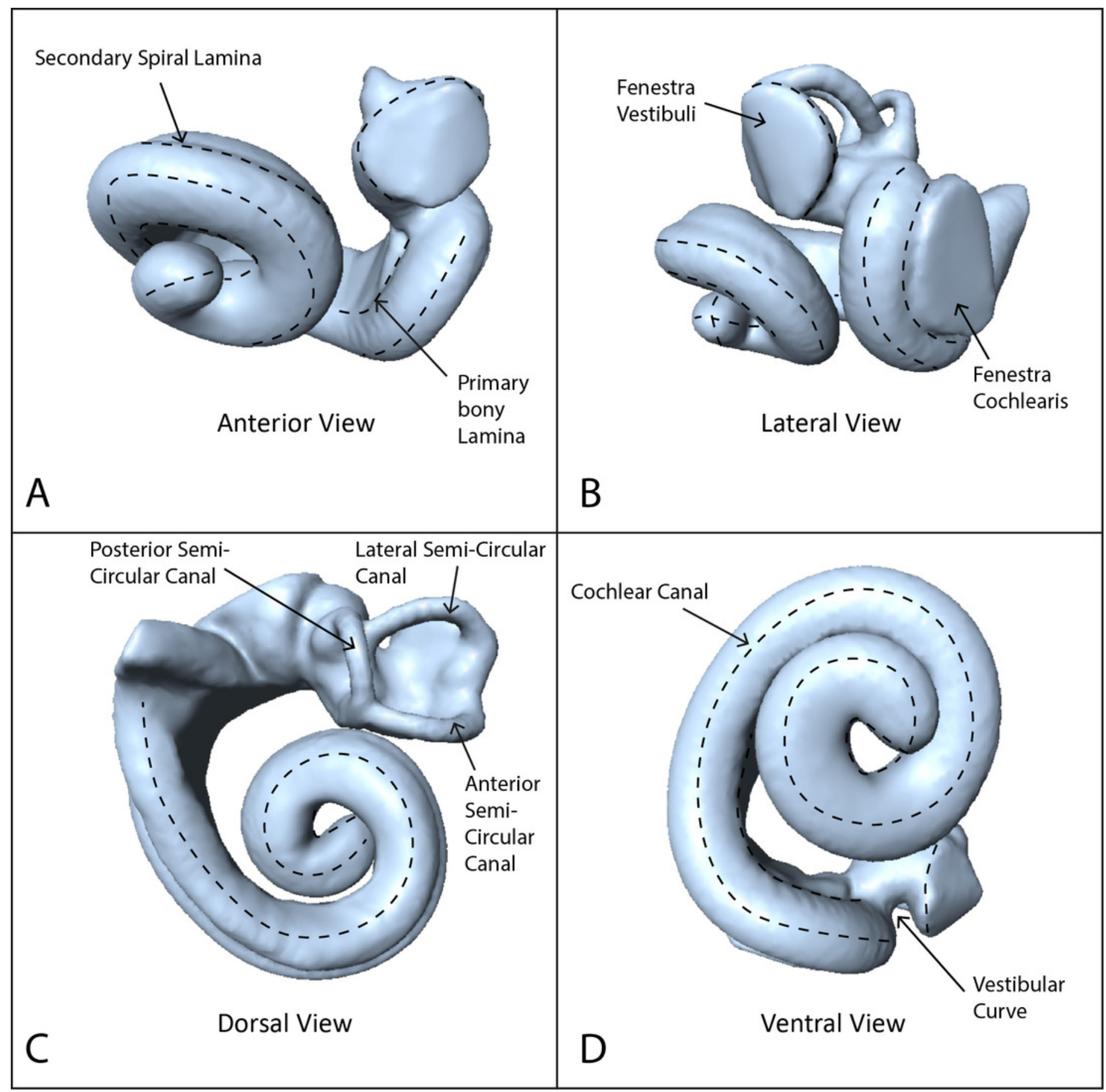


Figure 2

Line drawing of Phocoena phocoena (NHMUK_SW1934.31) cochlea in vestibular and posterior view, illustrating key measurements.

A-vestibular view, B-posterior view

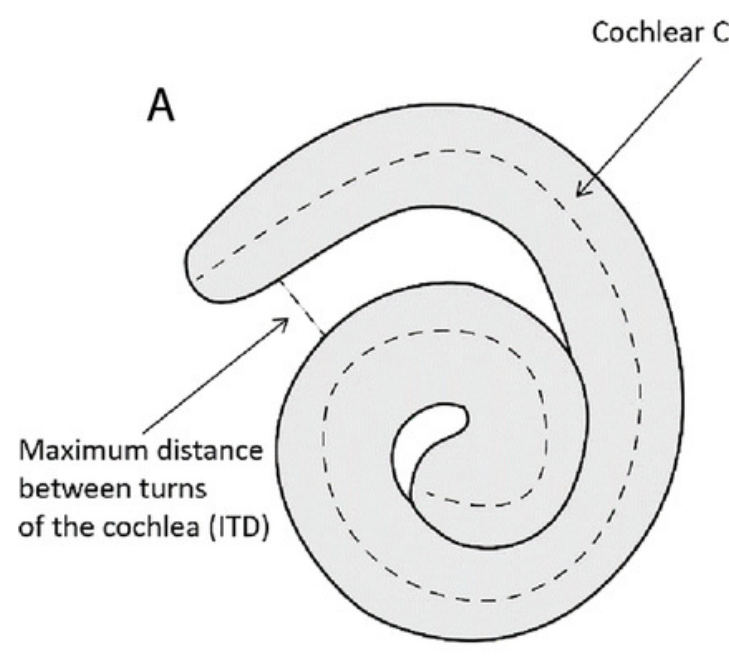

Vestibular View
B

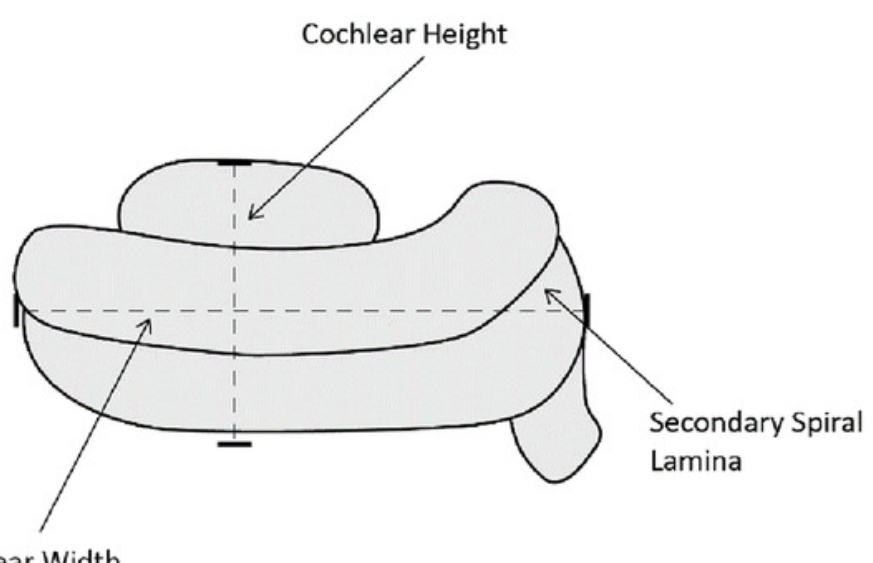

Cochlear Width

Posterior View 
Figure 3

Principal components (PC) plots for 3D cochlea shape data for PCs 1-3.

Purple points and convex hulls are Phocoena phocoena specimens; green points are all other odontocete species. Numbers in brackets show the percentage variance explained for each $P C$. 

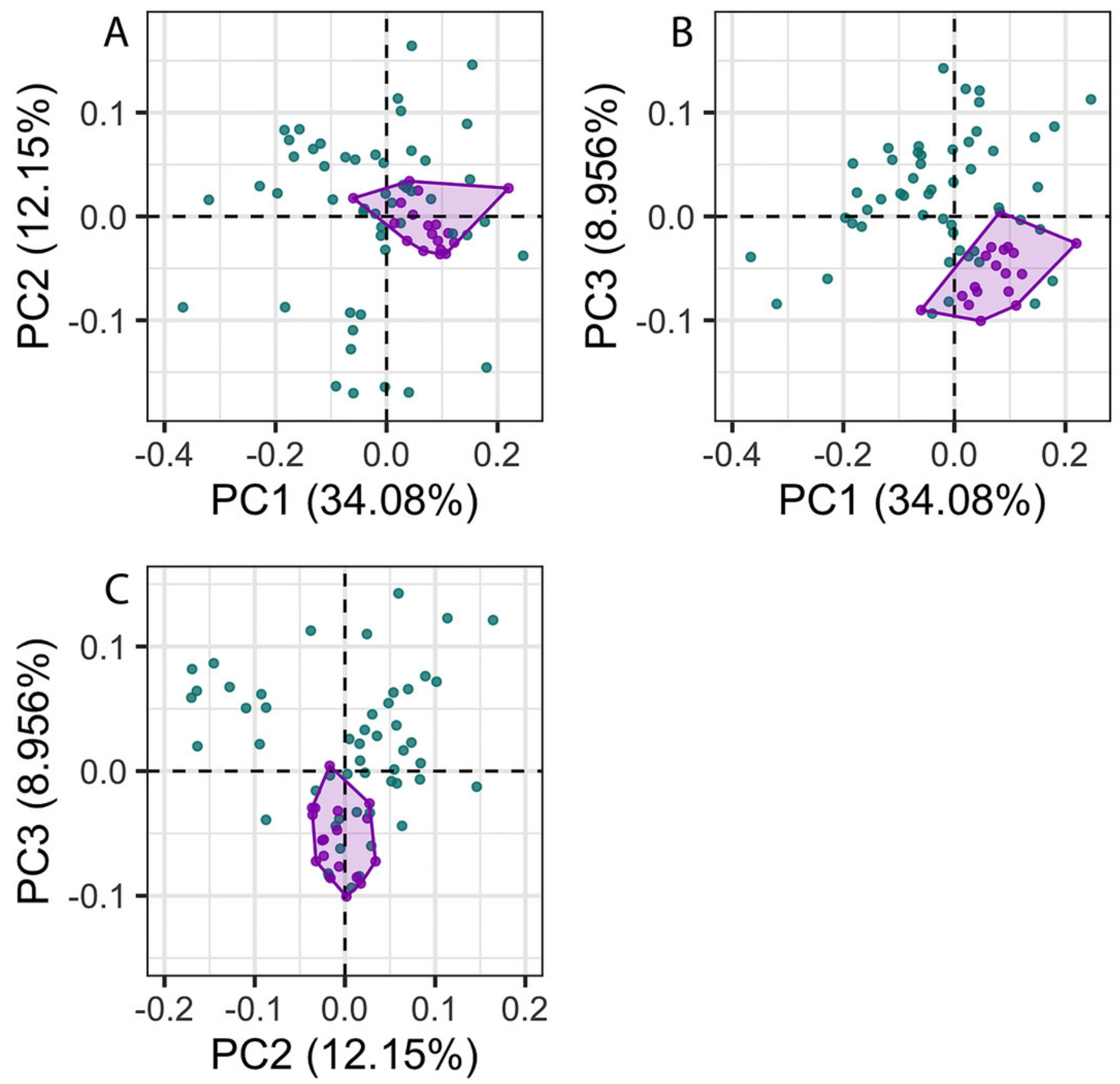
Figure 4

Cochleae of taxa near the extremes of the morphospace shown in figure 3 (not to scale)

A: Mesoplodon mirus (PC1 max); B: Globicephala melas (PC1 min); C: Sousa teuszii ; D:

Tasmacetus shepherdi. 
A

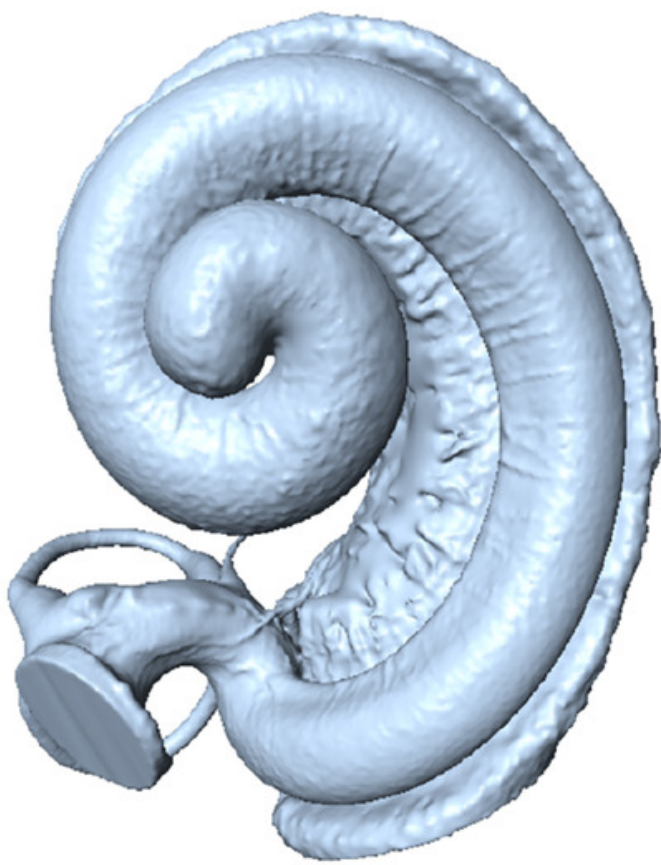

B

Mesoplodon

mirus

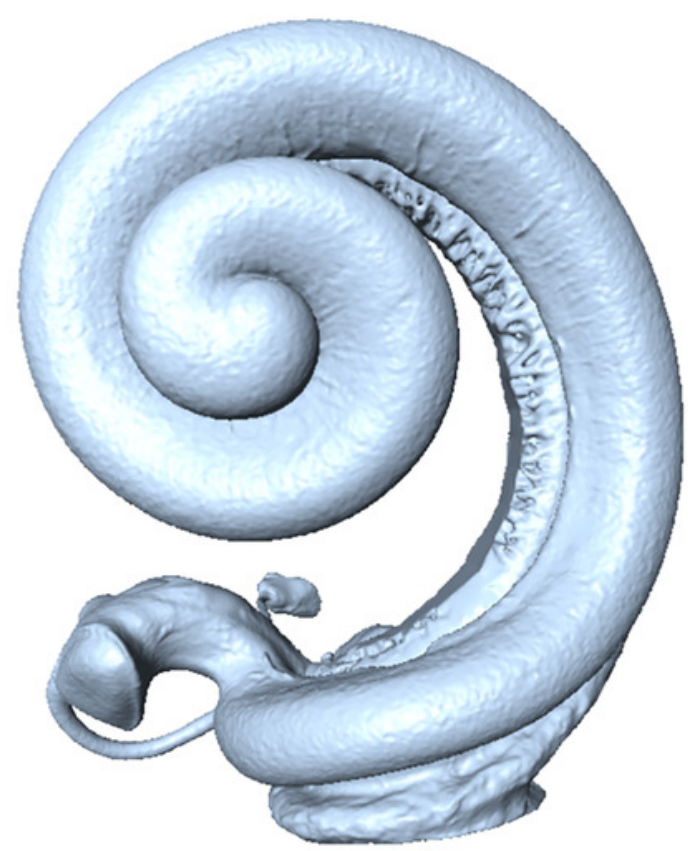

\section{Globicephala melas}
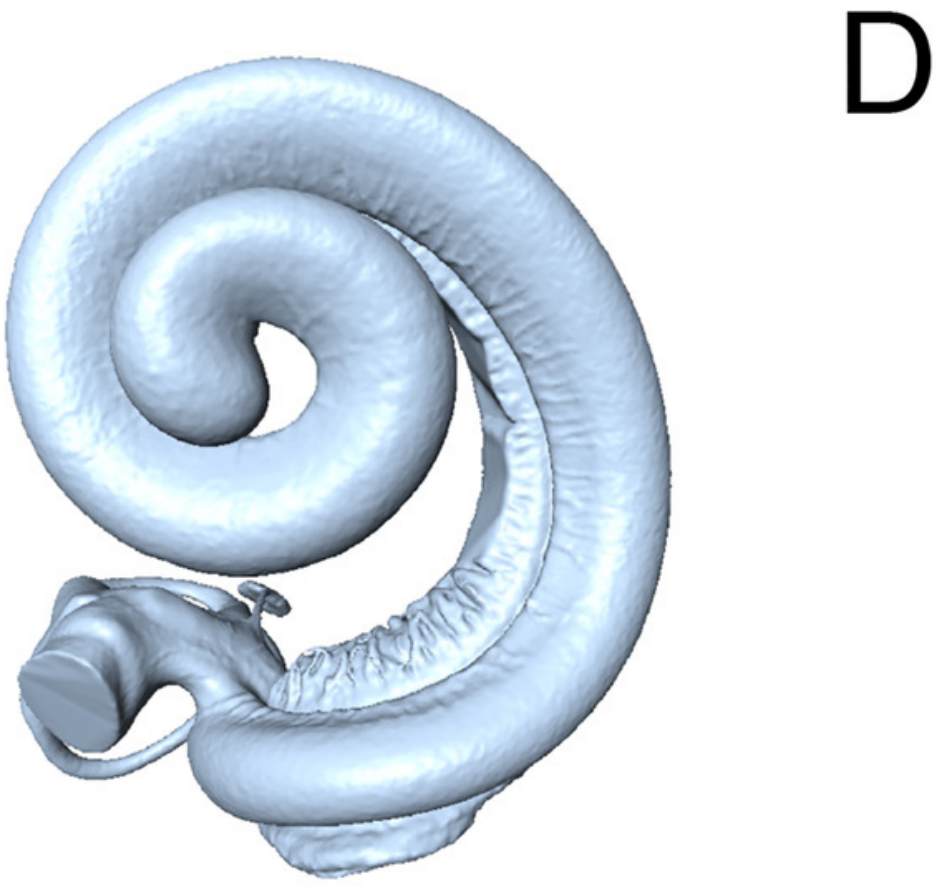

Sousa teuszii

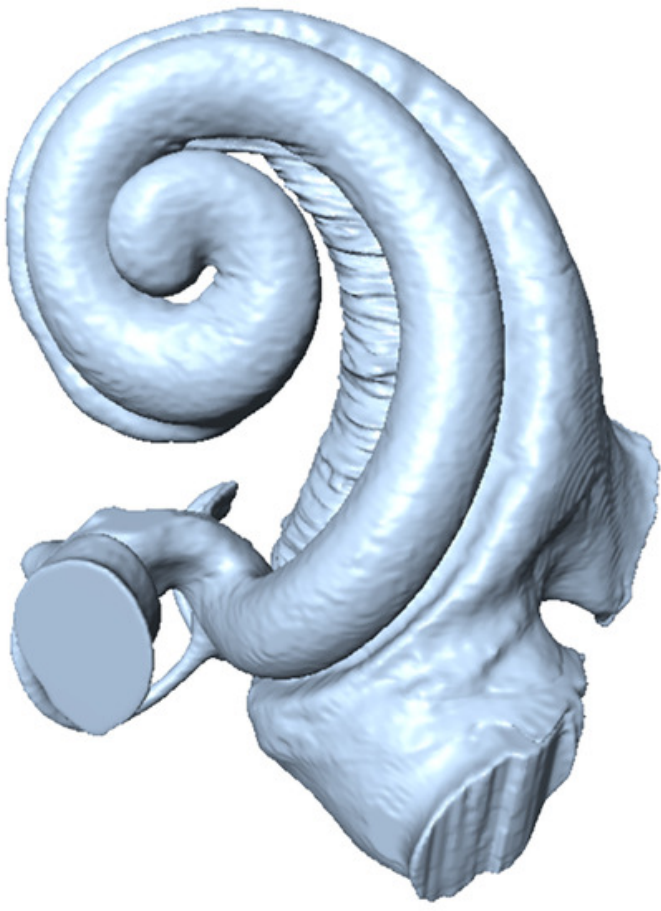

Tasmacetus shepherdi 